- Editorial Notes •

\title{
Preface to Special Topic on Atmospheric Greenhouse Gas Measurement and Application in China
}

\author{
Pengfei HAN ${ }^{1}$, Ning ZENG ${ }^{2}$, Bo YAO ${ }^{3}$, Weijian ZHOU ${ }^{4}$, Liqi CHEN ${ }^{5}$, Shaoqiang WANG ${ }^{6}$, Honggang LV7 ${ }^{7}$, \\ Wei XIAO ${ }^{8}$, Lingyun $\mathrm{ZHU}^{9}$, and Jiaping XU10 \\ ${ }^{1}$ State Key Laboratory of Numerical Modeling for Atmospheric Sciences and Geophysical Fluid Dynamics, Institute of \\ Atmospheric Physics, Chinese Academy of Sciences, Beijing 100029, China \\ ${ }^{2}$ Department of Atmospheric and Oceanic Science, University of Maryland, College Park, MD 20742, USA \\ ${ }^{3}$ Meteorological Observation Centre of China Meteorological Administration, Beijing 100081, China \\ ${ }^{4}$ Institute of Earth Environment, Chinese Academy of Sciences, Xi'an 710061, China \\ ${ }^{5}$ Third Institute of Oceanography, Ministry of Natural Resources, Xiamen 361005, China \\ ${ }^{6}$ Institute of Geographic Sciences and Natural Resources Research, Chinese Academy of Sciences, Beijing 100101, China \\ ${ }^{7}$ National Marine Environment Forecasting Center, Beijing 100081, China \\ ${ }^{8}$ Nanjing University of Information Science \& Technology, Nanjing 210044, China \\ ${ }^{9}$ Shanxi Institute of Meteorological Sciences, Taiyuan 030002, China \\ ${ }^{10}$ Jiangsu Institute of Meteorological Sciences, Nanjing 210009, China
}

Citation: Han, P. F., and Coauthors, 2020: Preface to Special Topic on Atmospheric Greenhouse Gas Measurement and Application in China. Adv. Atmos. Sci., 37(6), 555-556, https://doi.org/10.1007/s00376-020-9300-x.

China initiated a national carbon trading market in December 2017. Commitments and actions to reduce greenhouse gas (GHG) emissions require consistent, reliable and timely information on GHG emissions. GHG monitoring and modeling studies provide GHG emission estimates to evaluate and guide progress towards emission reductions. GHG monitoring has mainly focused on global-scale background networks over the last few decades, while recent efforts have been made on regional and urban scales, such as projects in the Beijing-Tianjin-Hebei city cluster, in Paris, Washington-Baltimore, Indianapolis, and Los Angeles. These "top-down" atmospheric observations, together with "bottom-up" GHG emissions inventories and biosphere fluxes, are integrated into GHG monitoring and application information systems. The Integrated Global Greenhouse Gas Information System (or IG ${ }^{3} I S$ ) was established by WMO/UNEP to facilitate such efforts after the 17th World Meteorological Congress. As one of the countries heavily impacted by climate change, China has implemented many actions to respond to climate change. Atmospheric GHG measurement techniques have been developed rapidly in China over the last decade, and this work has been applied in evaluating GHG emissions, identifying GHG sources, quantifying GHG fluxes, and supporting GHG-related policymaking.

The First China Greenhouse Gas Monitoring Conference was held in Beijing on 30th and 31st May 2019, which attracted more than 200 people from over 80 participating universities and institutes. This AAS-AOSL-ACCR joint special issue on "Atmospheric Greenhouse Gas Measurement and Application in China" provides a selection of research highlights from this conference. The selected papers cover all the sections of the conference, as follows:

(1) $\mathrm{CO}_{2}$ background monitoring. An example here is the paper by Mai et al. (2020), which measured background atmospheric $\mathrm{CO}_{2}$ and the potential source regions in the Pearl River Delta region.

(2) $\mathrm{CO}_{2}$ city area (emission sources) monitoring. The paper by Xiong et al. (2020) reports on a two-year observation of fossil-fuel $\mathrm{CO}_{2}$ spatial distribution in Xi' an City using ${ }^{14} \mathrm{C}$ isotope data. Also, Bao et al. (2020) present a novel study in which a low-cost non-dispersive infrared sensor was used to observe the vertical $\mathrm{CO}_{2}$ distribution in a high emissions area of Shijiazhuang, Hebei Province. Meanwhile, Zhang et al. (2020) conducted a three-year analysis of the variations and transmission characteristics of $\mathrm{CO}_{2}$ in Taiyuan, Shanxi Province.

(3) Non- $\mathrm{CO}_{2}$ GHG monitoring. Pu et al. (2020) estimated the hydrofluorocarbon emissions during 2012-16 in the Yangtze River Delta region based on weekly sampling at Lin'an Background Station, Zhejiang Province.

(4) GHG flux measurement. An example here is the work presented by Zhu et al. (2020), which compared the ozone 
fluxes over a maize field measured with gradient methods and the eddy covariance technique.

(5) New technologies and applications for GHG measurement. For instance, Ji et al. (2020) show the temporal and vertical distribution of methane in Xianghe derived from ground-based Fourier transform infrared and Picarro measurements. Using the Aircore method, Yi et al. (2020) conducted direct observations of atmospheric transport and stratosphere-troposphere exchange from $\mathrm{CO}_{2}$ profile measurements in Inner Mongolia.

(6) Applications of observational data. Fu et al. (2020) used a global chemical transport model (GEOS-Chem) and observations at 14 surface stations from the World Data Centre for Greenhouse Gases to study the sensitivity of the simulated $\mathrm{CO}_{2}$ concentration to interannual variations of its sources and sinks over East Asia.

These efforts provide accurate scientific understanding, technical support and solutions for major issues such as energy conservation and emissions reduction, carbon market transactions and low-carbon development. Along with this special issue, the China Carbon Monitoring Alliance (http://cma.sense1.cn/) is under way, and a data resources platform has also been established to provide opportunities for collaborations.

\section{REFERENCES}

Bao, Z. X., and Coauthors, 2020: Observation and modeling of vertical carbon dioxide distribution in a heavily polluted suburban environment. Atmospheric and Oceanic Science Letters, 13, 4, https://doi.org/10.1080/16742834.2020.1746627.

Fu, Y., H. Liao, X. J. Tian, H. Gao, Z. N. Cai, and R. Han, 2020: Sensitivity of the simulated $\mathrm{CO}_{2}$ concentration to inter-annual variations of $\mathrm{CO}_{2}$ sources and sinks over East Asia. Advances in Climate Change Research, https://doi.org/10.1016/j.accre.2020.03. 001 .

Ji, D. H., and Coauthors, 2020: Deriving temporal and vertical distributions of methane in Xianghe using ground-based Fourier transform infrared and gas-analyzer measurements. Adv. Atmos. Sci., 37(6), https://doi.org/10.1007/s00376-020-9233-4.

Mai, B. R., X. J. Deng, F. Zhang, H. He, T. Luan, F. Li, and X. Liu, 2020: Background characteristics of atmospheric $\mathrm{CO}_{2}$ and the potential source regions in the Pearl River Delta region of China. Adv. Atmos. Sci., 37(6), https://doi.org/10.1007/s00376-020-9238-z.

Pu, J. B., H. H., Xu, B. Yao, Y. Yu, Y. J. Jiang, Q. L. Ma, and L. Q. Chen, 2020: Estimate of hydrofluorocarbon emissions for 20122016 in the Yangtze River Delta, China. Adv. Atmos. Sci., 37(6), https://doi.org/10.1007/s00376-020-9242-3.

Xiong, X. H., and Coauthors, 2020: Two-year observation of fossil fuel carbon dioxide spatial distribution in Xi'an City. Adv. Atmos. Sci., https://doi.org/10.1007/s00376-020-9241-4.

Yi, Y., and Coauthors, 2020: Direct observations of atmospheric transport and stratosphere-troposphere exchange from high-precision carbon dioxide and carbon monoxide profile measurements. Adv. Atmos. Sci., 37(6), https://doi.org/10.1007/s00376-020-9227-2.

Zhang, F. S., L. Y. Zhu, S. M. Yan, X. A. Gao, and K. N. Pei, 2020: Analysis of the carbon dioxide mole fraction variation and its transmission characteristics in Taiyuan. Atmospheric and Oceanic Science Letters, https://doi.org/10.1080/16742834.2020.1737501.

Zhu, Z. L., X. Z. Tang, and F. H. Zhao, 2020: Comparison of ozone fluxes over a maize field measured with gradient methods and the eddy covariance technique. Adv. Atmos. Sci., 37(6), https://doi.org/10.1007/s00376-020-9217-4. 